Ensino, Saúde e Ambiente - V6 (2), pp. 1-19, ago. 2013

\title{
RISCOS DE ACIDENTES E DESASTRES EM ÁREA SUJEITA E NÃO SUJEITA A ENCHENTES NO MUNICÍPIO DE ITABORAÍ/RJ: A PERCEPÇÃO DOS PROFESSORES DO ENSINO FUNDAMENTAL.
}

\section{ACCIDENTS AND DISASTERS RISKS IN AREAS SUBJECT AND NOT SUBJECT TO FLOODING IN ITABORAÍ/RJ: THE PERCEPTION OF ELEMENTARY SCHOOL TEACHERS.}

\author{
Katia Mariana Holanda Barbosa ${ }^{1}$, José Rodrigo de Moraes², Mônica de Aquino Galeano \\ Massera da Hora $^{3}$ \\ ${ }^{1,3}$ Programa de Pós-graduação em Defesa e Segurança Civil/Universidade Federal Fluminense \\ (UFF), katiamariana@vm.uff.br, dahora@vm.uff.br \\ ${ }^{2}$ Departamento de Estatística/Universidade Federal Fluminense (UFF), jrodrigo78@est.uff.br
}

\begin{abstract}
Resumo
A educação sobre riscos de desastres no currículo escolar está prevista no novo §7o, art.26 da Lei no 9.394/1996. Com foco neste tema, este estudo buscou avaliar e comparar a percepção de riscos de desastres entre professores do ensino fundamental. Foram selecionadas cinco escolas públicas do ensino fundamental do município de Itaboraí-RJ, na área de influência do Complexo Petroquímico do Rio de Janeiro (Comperj), tendo como destaque os temas relacionados à defesa civil, especificamente na questão das enchentes. A percepção dos riscos de desastres de professores foi baseada numa pesquisa quantitativa em escolas situadas em área sujeita/não sujeita a enchentes. A divisão das escolas se baseou numa pesquisa qualitativa dirigida à direção das escolas e na avaliação fotográfica do entorno. A partir dos resultados, verificou-se a baixa percepção de riscos de desastres dos professores de ambos os grupos de escolas.
\end{abstract}

Palavras-chave: percepção de riscos de desastres, escolas, professores, enchentes.

\begin{abstract}
Education on disaster risk in the school curriculum is foreseen in the new $\S 7^{\circ}$, art.26 of Law 9.394/1996. Focusing on this issue, this study sought to evaluate and compare the perception of disaster risk among elementary school teachers. We selected five schools of public elementary school in Itaboraí municipality, area of influence of the Petrochemical Complex of Rio de Janeiro (Comperj), whose prominent themes related to civil defense, specifically on the issue of flooding. The perception of disaster risk teachers was based on a quantitative survey in schools in the area subject or not subject to flooding. The division of schools was based on a qualitative research directed toward the schools and photographic assessment of the surroundings. From the results, we concluded that there was a low perception by the teachers of the risk of disasters from both groups of schools.
\end{abstract}

Key-words: disaster risk perception, schools, teachers, flood. 


\section{INTRODUÇÃO}

A Organização das Nações Unidas (ONU) através da Estratégia Internacional para Redução de Desastres (EIRD), lançou em janeiro de 2005 uma campanha em nível internacional com o propósito de difundir nas escolas a conscientização sobre a redução de riscos de desastres e meios de promover o aumento da resiliência das nações e comunidades, sob o tema "A redução de desastres começa na escola", para o biênio 2006-2007. O lançamento dessa campanha se deu durante a Conferência Mundial sobre Redução de Desastres, em Hyogo, no Japão. Na ocasião, o Brasil e outros 167 países assinaram o compromisso de promover ações que aumentassem a resiliência das nações frente aos desastres. A campanha defendeu a integração da educação sobre riscos de desastres no currículo escolar para que os jovens, com grau de conscientização difundido por seus professores, através da escola, desempenhem papel importante no salvamento de vidas e proteção contra desastres.

De acordo com CEPED/UFSC (2012), resiliência é definida como a habilidade de um sistema, comunidade ou sociedade exposta a riscos, resistir, absorver, acomodarse e reagir aos efeitos de ameaças de maneira eficiente e em tempo adequado, incluindo preservação e reconstrução de suas estruturas e serviços essenciais básicos. Segundo os estudos realizados por CEPED/UFSC (2012):

"No contexto brasileiro, a Campanha Nacional pretende fortalecer a cultura de riscos de desastres, em detrimento da cultura de desastres, em que a primeira contempla uma visão mais ampla de causas $e$ consequências, vulnerabilidades e ameaças, prevenção e preparação, identificação e mapeamento de riscos, e a segunda limita-se a uma abordagem passiva, notadamente de resposta a desastres $e$ assistência a afetados” (p.15).

Os desastres naturais ocorridos no Brasil, de forma recorrente, têm assumido grandes proporções e trouxeram à tona o tema defesa civil ao cenário nacional com prioridade na agenda governamental. Os órgãos de defesa civil no país, antes direcionados para ações emergenciais, de respostas e reconstrução durante os desastres, passaram a dar ênfase à prevenção.

A Política Nacional de Defesa Civil (PNDC) sofreu alterações ao longo dos anos e com a publicação da Lei $\mathrm{n}^{\mathrm{o}} 12.608$ de 10/04/2012, foi incluído o termo "Proteção", passando a denominar-se "Política Nacional de Proteção e Defesa Civil (PNPDEC)". Dentre os objetivos da PNPDEC, estão: “desenvolver a consciência 
nacional acerca dos riscos de desastre", bem como "orientar as comunidades a adotar comportamentos adequados de prevenção e de resposta em situação de desastre e promover a autoproteção". Outra mudança importante foi a inclusão do $\S 7^{\circ}$, ao Art. 26 da Lei $n^{\circ} 9.394$ de 20/12/1996 - Lei de Diretrizes e Bases da Educação Nacional - que estabelece que "os currículos do ensino fundamental e médio devem incluir os princípios da proteção e defesa civil e a educação ambiental de forma integrada aos conteúdos obrigatórios".

O momento atual é de reflexão quanto às ações que estão sendo tomadas para mudança deste cenário de desastres em nosso país.

Com base no exposto, buscou-se desenvolver no presente artigo uma avaliação e comparação da percepção de riscos de desastres existente entre professores do ensino fundamental e, a partir dessa análise, avaliar a necessidade de promoção da cultura da percepção de riscos de desastres, de forma a contribuir para a redução da vulnerabilidade e conscientização do cidadão. Para alcançar o objetivo proposto, foram selecionadas cinco escolas públicas do ensino fundamental do município de Itaboraí, Estado do Rio de Janeiro, na área de influência do Complexo Petroquímico do Rio de Janeiro (Comperj), um dos principais empreendimentos da história da Petrobras (Marroig et al., 2011). As escolas foram divididas em dois grupos, a saber: grupo 1, localizada em área de risco de enchentes, e grupo 2, não localizada em área de risco de enchentes.

\section{MATERIAL E MÉTODOS}

Os dados utilizados no presente artigo são provenientes de uma pesquisa quantitativa dirigida a professores de cinco escolas públicas do $5^{\circ}$ ao $9^{\circ}$ ano do Ensino Fundamental: 1) E.M. Guilherme de Miranda Saraiva, 2) E.M. Padre Hugo Montedônio Rêgo, 3) E.M. Afonso Salles, 4) E.M. Luzia Gomes de Oliveira e, 5) E.M. Geremias de Mattos Fontes. A Figura 1 apresenta o mapa de localização do entorno do Comperj com as cinco escolas. 


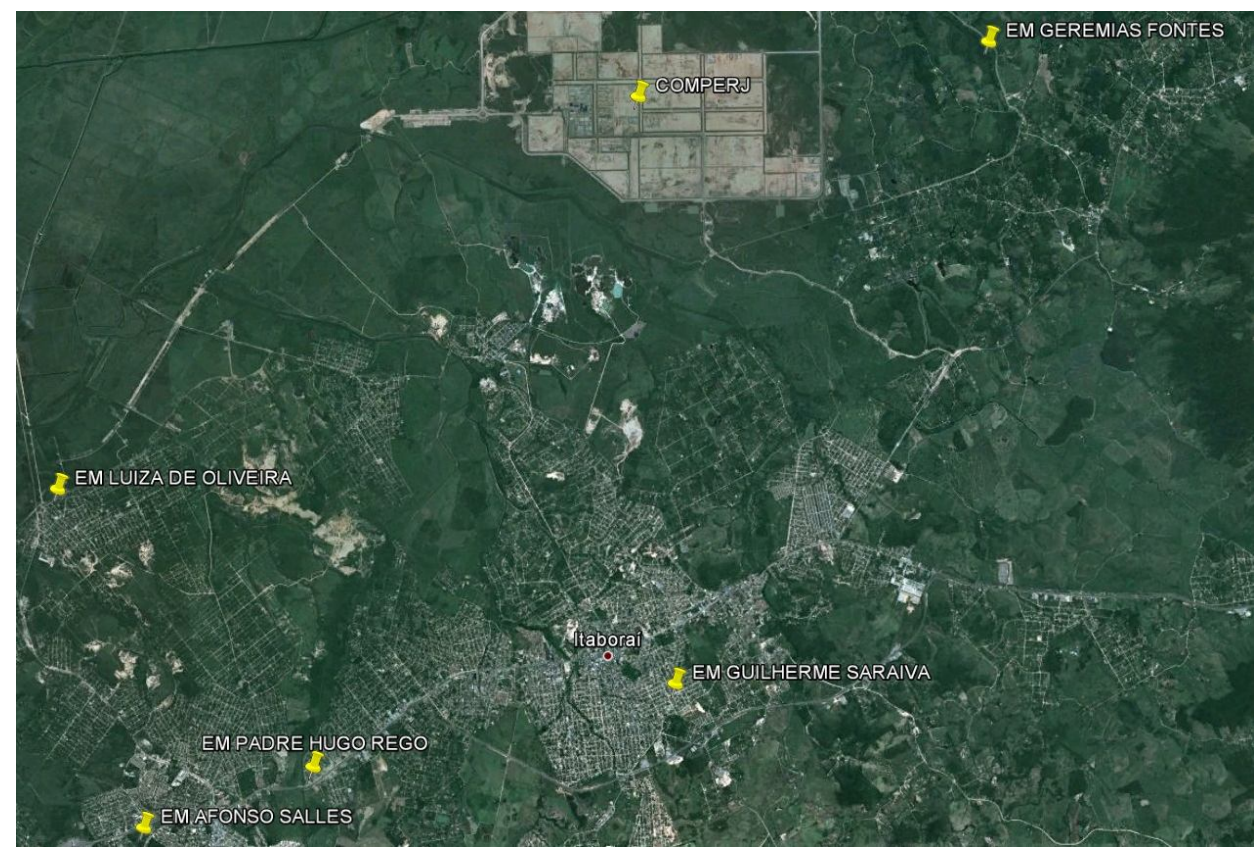

Figura 1- Mapa de localização das cinco Escolas Municipais e do Comperj

Fonte: Google Earth

A pesquisa teve como destaque os temas relacionados à defesa civil, com foco na questão dos desastres oriundos de enchentes e a percepção dos professores do ensino fundamental que atuam em escolas públicas do município de Itaboraí-RJ, sobre riscos de acidentes e desastres.

$\mathrm{O}$ instrumento de coleta de dados da pesquisa quantitativa foi um questionário padronizado que contém quesitos para avaliar a conscientização dos professores do ensino fundamental sobre riscos de acidentes e desastres, que incluem basicamente perguntas sobre temas em defesa civil abordados pelos professores, meios utilizados para inclusão desses temas, origem da iniciativa para o desenvolvimento de atividades de prevenção, tipos de projetos desenvolvidos nas escolas e as suas principais características.

Para a realização da pesquisa quantitativa, foram inicialmente realizadas reuniões com os diretores, coordenadores e professores dessas cinco escolas onde foi explanada a proposta da pesquisa. Posteriormente, foi realizada uma reunião com a Coordenação da Divisão do $2^{\circ}$ segmento do Ensino Fundamental da Subsecretaria de Gestão e Ensino da Secretaria Municipal de Educação e Cultura do município, visando obter permissão para realização da pesquisa qualitativa com a direção das cinco escolas e para fotografar o seu entorno. Na pesquisa qualitativa, foram registrados os relatos da 
direção quanto aos problemas mais frequentes enfrentados pela escola, com relação a enchentes e inundações na região. Além disso, na ocasião da entrevista, foi visitado e fotografado o entorno dessas cinco escolas para verificar a existência de rios e valões que pudessem corroborar os problemas apontados pela direção.

A entrega dos questionários aos cinco diretores de cada escola contemplada foi feita por intermédio da Secretaria de Educação do Município de Itaboraí, que, por sua vez, os entregou aos professores que aceitaram participar da pesquisa. O período de realização da pesquisa compreendeu os meses de junho a setembro de 2011.

A população de estudo foi constituída de 70 professores, na faixa etária de 21 a 54 anos, de ambos os sexos (50\% de homens e 50\% de mulheres).

\subsection{Variáveis identificadas}

A variável "grupo de escola" é composta por dois níveis, denominados de grupo 1 e grupo 2. O grupo 1 é formado pelas escolas localizadas em área sujeita a risco de enchentes: E.M. Padre Hugo Montedônio Rêgo, E.M. Afonso Salles, E.M. Luzia Gomes de Oliveira, E.M. Geremias de Mattos Fontes. O grupo 2, por sua vez, é composto por uma única escola: E.M. Guilherme de Miranda Saraiva, que não sofre com problemas de enchentes.

Como as perguntas do questionário admitiram respostas múltiplas (o professor poderia escolher mais de uma alternativa de resposta), as demais variáveis de estudo, identificadas conforme a itemização adotada no questionário, foram tratadas de forma dicotômica (sim, não). Essas variáveis referem-se a: 1) temas relacionados à defesa civil abordados pelos professores; 2) meios utilizados para inclusão do(s) tema(s); 3) origens da iniciativa para o desenvolvimento de atividades de prevenção (própria, da direção, da comunidade, dos alunos, instituições externas); 4) tipos de projetos desenvolvidos nas escolas; e, 5) principais características do(s) projeto(s).

\subsection{Análise dos dados}

A análise estatística foi desenvolvida por meio da construção de distribuições de frequência dos professores, segundo cada uma das variáveis de estudo relativas ao contexto de desastres e riscos, em especial de enchentes, nos dois grupos de escolas. Avaliou-se a homogeneidade das distribuições dessas variáveis nesses dois grupos de escolas por meio do teste quiquadrado, considerando o nível de significância de $10 \%$ (p- 
valor $\leq 0,10)$. A análise estatística foi realizada utilizando o software SPSS for Windows, versão 18 .

Por fim, foi desenvolvida uma análise qualitativa, a partir dos relatos dos diretores de cada uma das cinco escolas. Vale destacar que a identificação da vulnerabilidade das escolas às enchentes e inundações em época de chuvas foi realizada através de visitas de campo, registro fotográfico e entrevistas com as direções de cada escola.

\section{RESULTADOS ENCONTRADOS}

A partir das visitas de campo e dos relatos dos diretores, foi possível identificar que quatro das cinco escolas estão localizadas em área sujeita a risco de enchentes: E.M. Padre Hugo Montedônio Rêgo, E.M. Afonso Salles, E.M. Luzia Gomes de Oliveira, E.M. Geremias de Mattos Fontes. Apenas a escola E.M. Guilherme de Miranda Saraiva, não está situada em área sujeita a risco de enchentes.

Relatos da direção da E.M. Geremias de Mattos Fontes apontam a ocorrência de transbordamentos e alagamentos em dias de chuva provocados por um lago de propriedade particular, rios e valões de esgoto a céu aberto, existentes nas ruas do entorno e na região. Não há pavimentação nas ruas do entorno nem nas ruas próximas à escola, como ilustrado na Foto 1.

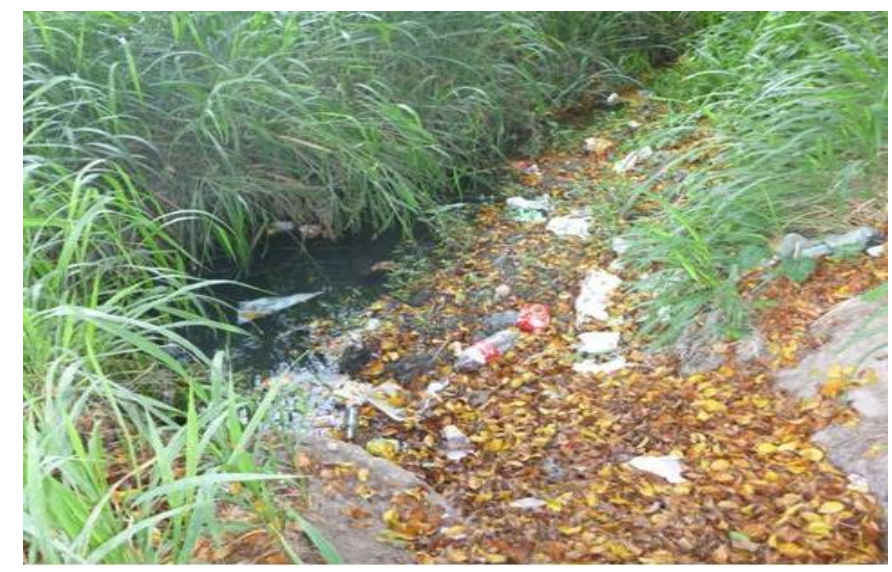

Foto 1 - Valão no entorno da E.M. Geremias de Mattos Fontes

Fonte: Autor

A E.M Luzia Gomes de Oliveira, está localizada em região cortada pelo rio Macacu e tributários que contribuem com enchentes e alagamentos em época de chuvas com significativas perdas materiais, embora as ruas do entorno tenham pavimentação, Foto 2. A população da região é muito carente de infraestrutura de saneamento. 


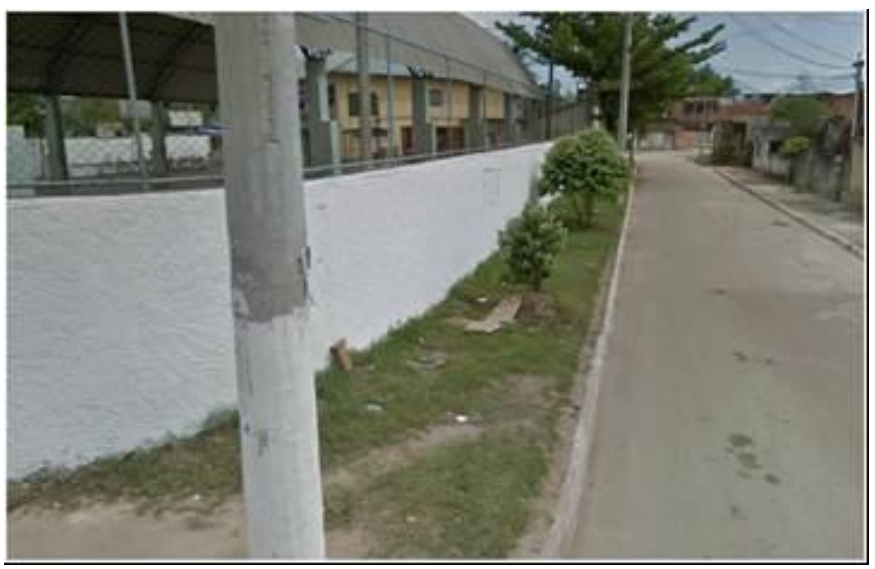

Foto 2 - Lateral e fundos da E.M. Luzia Gomes de Oliveira

Fonte: Autor

A E.M Afonso Salles fica às margens da Rodovia BR-101 e o acesso é feito por uma passarela sobre um valão de esgoto a céu aberto, Foto 3. Segundo a direção o valão transborda em dias de chuvas, impedindo o acesso à escola.

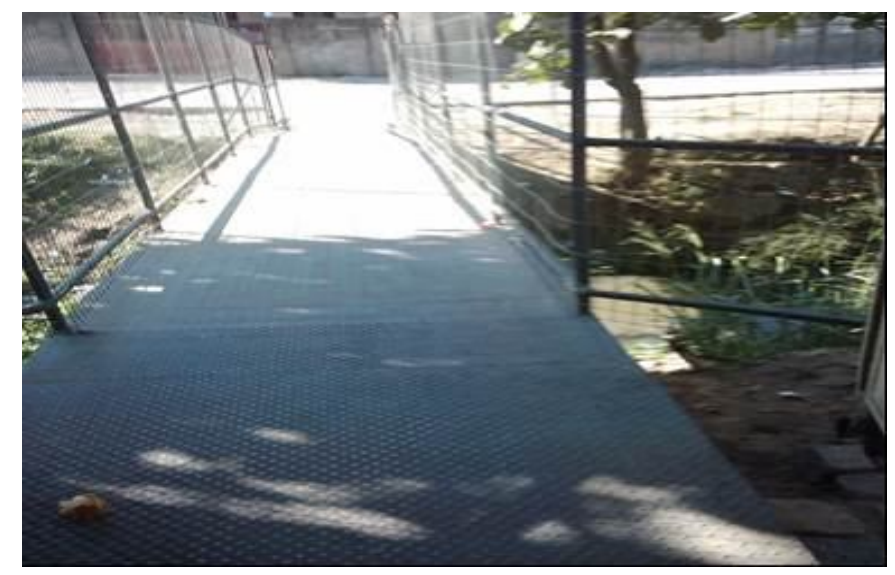

Foto 3 - Ponte que liga a rua à entrada principal da E.M. Afonso Salles.

Fonte: Autor

A E.M Padre Hugo Montedônio Rêgo também está situada às margens da Rodovia BR-101. Nas proximidades da escola há um rio e um valão de esgoto a céu aberto, as ruas não são pavimentadas no entorno nem nas comunidades próximas (Foto 4) e, segundo relato da direção, as enchentes provocam alagamentos constantes na comunidade que também é carente de serviços básicos de saneamento. 


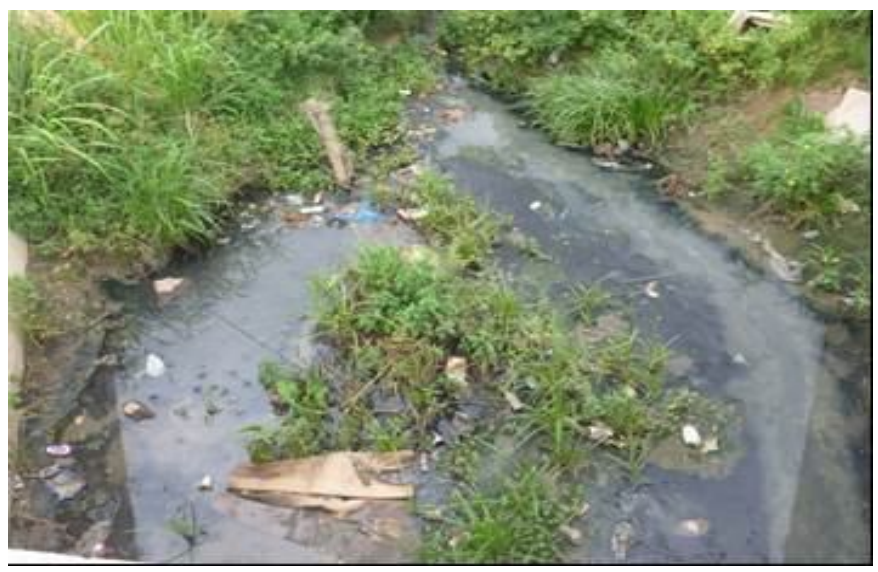

Foto 4 - Valão em frente à E.M. Padre Hugo Montedônio Rêgo.

Fonte: Autor

Quanto à E. M. Guilherme de Miranda Saraiva, a avaliação fotográfica e a análise qualitativa permitiram detectar a inexistência de problemas relacionados a enchentes, por estar localizada em terreno alto, no centro da cidade, próxima a toda infraestrutura do município (grandes lojas comerciais, cartórios, praças, restaurantes, bares, entre outros), e por possuir ruas pavimentadas em seu entorno e escoamento de águas pluviais, Foto 5 .

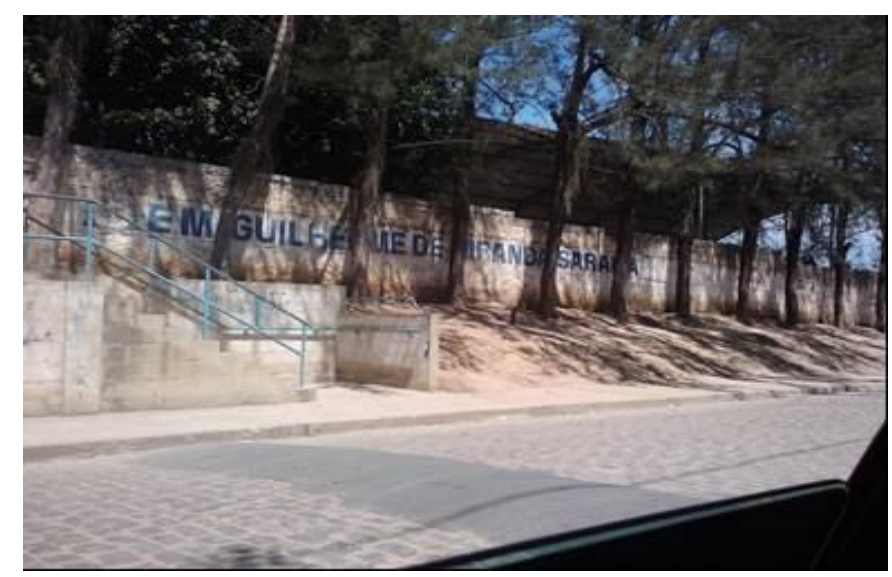

Foto 5 - Entrada principal da E.M. Guilherme de Miranda Saraiva

Fonte: Autor 
Com relação à análise estatística, a Tabela 1 apresenta a distribuição percentual dos professores do ensino fundamental por grupo de escolas que tenham abordado ou não temas relacionados à defesa civil de maneira geral. No grupo de escolas sujeitas a enchentes (grupo 1), foram observadas as maiores proporções de professores abordando os seguintes temas: Poluição da água (54,5\%), Enchentes e inundações (48,5\%), Ações humanitárias (48,5\%), Desastres naturais (45,5\%), Mudanças climáticas (42,4\%), Acidentes na escola (42,4\%), Chuvas intensas (39,4\%) e Doenças epidêmicas $(39,4 \%)$.

No grupo de escola não sujeita a enchentes (grupo 2) foram observadas as maiores proporções de professores abordando os seguintes temas: Poluição da água (59,5\%), Ações humanitárias (51,4\%), Desastres Naturais (45,9\%), Mudanças climáticas (43,2\%), Doenças epidêmicas (43,2\%), Enchentes e inundações (40,5\%), Desastres humanos $(37,8 \%)$ e Deslizamentos de terra $(32,4 \%)$.

Ao comparar ambos os grupos de escolas, verificou-se diferença estatisticamente significante entre as proporções de professores que abordaram o tema Riscos de acidentes ( $\mathrm{p}$-valor=0,077), sendo esta proporção maior para o grupo de escolas localizadas em área sujeita a enchentes (grupo 1: 27,3\% vs grupo 2: 10,8\%). No que tange aos temas relacionados à questão das enchentes e inundações, foco principal deste trabalho, como Desastres naturais, Deslizamentos de terra, Mudanças climáticas, Chuvas intensas, Enchentes e inundações, Enxurradas e Doenças Epidêmicas, observou-se proporções semelhantes de professores que abordaram tais temas nos dois grupos de escolas (p-valor $>0,10$ ). Verificou-se ainda que é a minoria dos professores, em ambos os grupos (grupo 1: variando de 24,2 a 48,5\%; e grupo 2: variando de 27,0 a $45,9 \%)$, que está abordando temas relacionados à questão de enchentes em suas disciplinas.

Tabela 1 - Distribuição percentual dos professores do ensino fundamental por grupo de escolas segundo a abordagem ou não de temas.

\begin{tabular}{|c|c|c|c|c|c|c|c|}
\hline \multirow{3}{*}{ Temas* } & \multicolumn{4}{|c|}{ Grupo de escola } & \multirow{2}{*}{\multicolumn{2}{|c|}{ Total }} & \multirow{3}{*}{$\begin{array}{c}\begin{array}{c}\text { Teste } \\
\text { quiquadrado }\end{array} \\
\text { p-valor } \\
\end{array}$} \\
\hline & \multicolumn{2}{|c|}{$\begin{array}{c}\text { sujeita a } \\
\text { enchentes }\end{array}$} & \multicolumn{2}{|c|}{$\begin{array}{c}\text { não sujeita a } \\
\text { enchentes }\end{array}$} & & & \\
\hline & $\mathbf{n}$ & $\%$ & $\mathbf{n}$ & $\%$ & n & $\%$ & \\
\hline \multicolumn{8}{|c|}{ Riscos de acidentes } \\
\hline Sim & 9 & 27,3 & 4 & 10,8 & 13 & 18,6 & \multirow{2}{*}{0,077} \\
\hline Não & 24 & 72,7 & 33 & 89,2 & 57 & 81,4 & \\
\hline \multicolumn{8}{|c|}{ Acidentes domésticos } \\
\hline Sim & 8 & 24,2 & 4 & 10,8 & 12 & 17,1 & \multirow{2}{*}{0,137} \\
\hline Não & 25 & 75,8 & 33 & 89,2 & 58 & 82,9 & \\
\hline \multicolumn{8}{|c|}{ Acidentes de transportes } \\
\hline Sim & 5 & 15,2 & 4 & 10,8 & 9 & 12,9 & 0,588 \\
\hline
\end{tabular}


Ensino, Saúde e Ambiente -V6 (2), pp. 1-19, ago. 2013

\begin{tabular}{|c|c|c|c|c|c|c|c|}
\hline Não & 28 & 84,8 & 33 & 89,2 & 61 & 87,1 & \\
\hline \multicolumn{8}{|c|}{ Acidentes na escola } \\
\hline Sim & 14 & 42,4 & 11 & 29,7 & 25 & 35,7 & \multirow{2}{*}{0,269} \\
\hline Não & 19 & 57,6 & 26 & 70,3 & 45 & 64,3 & \\
\hline \multicolumn{8}{|c|}{ Desastres Naturais } \\
\hline Sim & 15 & 45,5 & 17 & 45,9 & 32 & 45,7 & \multirow{2}{*}{0,967} \\
\hline Não & 18 & 54,5 & 20 & 54,1 & 38 & 54,3 & \\
\hline \multicolumn{8}{|c|}{ Desastres Humanos } \\
\hline Sim & 10 & 30,3 & 14 & 37,8 & 24 & 34,3 & \multirow{2}{*}{0,507} \\
\hline Não & 23 & 69,7 & 23 & 62,2 & 46 & 65,7 & \\
\hline \multicolumn{8}{|c|}{ Comportamento de risco } \\
\hline Sim & 12 & 36,4 & 10 & 27,0 & 22 & 31,4 & \multirow{2}{*}{0,401} \\
\hline Não & 21 & 63,6 & 27 & 73,0 & 48 & 68,6 & \\
\hline \multicolumn{8}{|c|}{ Desastres Tecnológicos } \\
\hline Sim & 3 & 9,1 & 8 & 21,6 & 11 & 15,7 & \multirow{2}{*}{0,150} \\
\hline Não & 30 & 90,9 & 29 & 78,4 & 59 & 84,3 & \\
\hline \multicolumn{8}{|c|}{ Ações Humanitárias } \\
\hline Sim & 16 & 48,5 & 19 & 51,4 & 35 & 50,0 & \multirow{2}{*}{0,811} \\
\hline Não & 17 & 51,5 & 18 & 48,6 & 35 & 50,0 & \\
\hline \multicolumn{8}{|c|}{ Voluntariado } \\
\hline Sim & 9 & 27,3 & 9 & 24,3 & 18 & 25,7 & \multirow{2}{*}{0,778} \\
\hline Não & 24 & 72,7 & 28 & 75,7 & 52 & 74,3 & \\
\hline \multicolumn{8}{|c|}{ Doenças Epidêmicas } \\
\hline Sim & 13 & 39,4 & 16 & 43,2 & 29 & 41,4 & \multirow{2}{*}{0,744} \\
\hline Não & 20 & 60,6 & 21 & 56,8 & 41 & 58,6 & \\
\hline \multicolumn{8}{|c|}{ Poluicão da água } \\
\hline Sim & 18 & 54,5 & 22 & 59,5 & 40 & 57,1 & \multirow{2}{*}{0,678} \\
\hline Não & 15 & 45,5 & 15 & 40,5 & 30 & 42,9 & \\
\hline \multicolumn{8}{|c|}{ Chuvas intensas } \\
\hline Sim & 13 & 39,4 & 10 & 27,0 & 23 & 32,9 & 0271 \\
\hline Não & 20 & 60,6 & 27 & 73,0 & 47 & 67,1 & 0,271 \\
\hline Enchen & & & & & & & \\
\hline Sim & 16 & 48,5 & 15 & 40,5 & 31 & 44,3 & \\
\hline Não & 17 & 51,5 & 22 & 59,5 & 39 & 55,7 & 0,504 \\
\hline Enxurr & & & & & & & \\
\hline Sim & 8 & 24,2 & 11 & 29,7 & 19 & 27,1 & \\
\hline Não & 25 & 75,8 & 26 & 70,3 & 51 & 72,9 & 0,606 \\
\hline Deslizaı & & & & & & & \\
\hline Sim & 10 & 30,3 & 12 & 32,4 & 22 & 31,4 & \\
\hline Não & 23 & 69,7 & 25 & 67,6 & 48 & 68,6 & 0,848 \\
\hline Raios & & & & & & & \\
\hline Sim & 3 & 9,1 & 5 & 13,5 & 8 & 11,4 & \\
\hline Não & 30 & 90,9 & 32 & 86,5 & 62 & 88,6 & 0,562 \\
\hline Incêndi & & & & & & & \\
\hline Sim & 5 & 15,2 & 3 & 8,1 & 8 & 11,4 & \\
\hline Não & 28 & 84,8 & 34 & 91,9 & 62 & 88,6 & 0,355 \\
\hline Mudan & & & & & & & \\
\hline Sim & 14 & 42,4 & 16 & 43,2 & 30 & 42,9 & \\
\hline Não & 19 & 57,6 & 21 & 56,8 & 40 & 57,1 & 0,945 \\
\hline $\begin{array}{l}\text { Normas } \\
\text { acident }\end{array}$ & & & & & & & \\
\hline Sim & 2 & 6,1 & 1 & 2,7 & 3 & 4,3 & 0.489 \\
\hline Não & 31 & 93,9 & 36 & 97,3 & 67 & 95,7 & 0,489 \\
\hline
\end{tabular}

$\mathrm{Na}$ análise de como os professores incluem temas relacionados à defesa civil, ilustrada na Tabela 2, não foi verificada diferença estatisticamente significante (pvalor $>0,10)$, em ambos os grupos de escolas, entre as proporções de professores que 
utilizaram os meios de inclusão do(s) tema(s): realização de pesquisa, produção de material, exploração de conteúdos da disciplina, uso de problemas da comunidade ou escola, realização de palestras/seminários, desenvolvimento com parcerias e abordagem da questão da resiliência.

Tabela 2 - Distribuição percentual dos professores do ensino fundamental por grupo de escolas, segundo os meios utilizados para inclusão de temas.

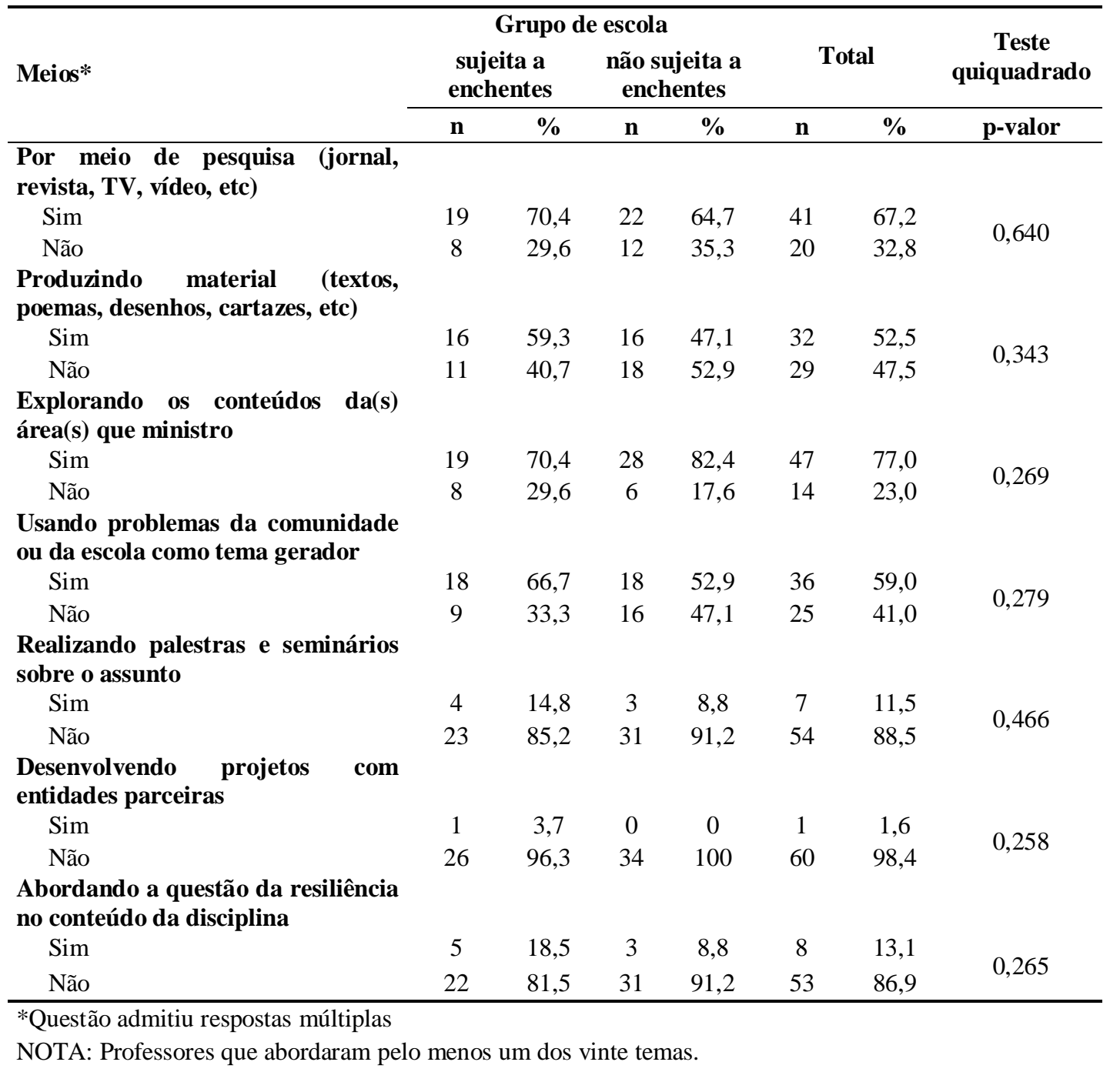

Da análise da Tabela 2 pode-se inferir que para os dois grupos de escolas foram observadas as maiores proporções de professores utilizando os seguintes meios: exploração de conteúdos da disciplina ministrada (grupo 1: 70,4\% vs grupo 2: 82,4\%), realização de pesquisa (grupo 1: $70,4 \%$ vs grupo 2: 64,7\%), uso de problemas da 
comunidade ou da escola (grupo 1: $66,7 \%$ vs grupo 2: 52,9\%) e produção de material (grupo 1: 59,3\% vs grupo 2: 47,1\%).

A proporção de professores que participaram das atividades de prevenção por iniciativa da comunidade e por iniciativa de instituições externas foi significativamente maior nas escolas sujeitas a enchentes do que na escola não sujeita a enchentes (pvalor $\leq 0,10)$. Para as demais iniciativas não se observou diferença estatisticamente significante entre a proporção de professores que desenvolveram as atividades de prevenção, como ilustrado na Tabela 3 . As iniciativas mais frequentes que explicam a participação dos professores nas atividades de prevenção, em ambos os grupos de escolas, foram a própria (grupo 1: 85,2\% vs grupo 2: 82,4\%), da direção (grupo 1: $29,6 \%$ vs grupo 2:23,5\%) e dos alunos (grupo 1:25,9\% vs grupo 2: 20,6\%).

Tabela 3 - Distribuição percentual dos professores do ensino fundamental por grupo de escolas, segundo a iniciativa para o desenvolvimento das atividades de prevenção.

\begin{tabular}{|c|c|c|c|c|c|c|c|}
\hline \multirow{3}{*}{ Iniciativas* } & \multicolumn{4}{|c|}{ Grupo de escola } & \multirow{2}{*}{\multicolumn{2}{|c|}{ Total }} & \multirow{3}{*}{$\begin{array}{c}\begin{array}{c}\text { Teste } \\
\text { quiquadrado }\end{array} \\
\text { p-valor } \\
\end{array}$} \\
\hline & \multicolumn{2}{|c|}{$\begin{array}{c}\text { sujeita a } \\
\text { enchentes }\end{array}$} & \multicolumn{2}{|c|}{$\begin{array}{c}\text { não sujeita a } \\
\text { enchentes }\end{array}$} & & & \\
\hline & $\mathbf{n}$ & $\%$ & $\mathbf{n}$ & $\%$ & $\mathbf{n}$ & $\%$ & \\
\hline \multicolumn{8}{|l|}{ Própria } \\
\hline Sim & 23 & 85,2 & 28 & 82,4 & 51 & 83,6 & \multirow{2}{*}{0,767} \\
\hline Não & 4 & 14,8 & 6 & 17,6 & 10 & 16,4 & \\
\hline \multicolumn{8}{|l|}{ Direção } \\
\hline Sim & 8 & 29,6 & 8 & 23,5 & 16 & 26,2 & \multirow{2}{*}{0,591} \\
\hline Não & 19 & 70,4 & 26 & 76,5 & 45 & 73,8 & \\
\hline \multicolumn{8}{|l|}{ Comunidade } \\
\hline Sim & 2 & 7,4 & 0 & 0 & 2 & 3,3 & \multirow{2}{*}{0,107} \\
\hline Não & 25 & 92,6 & 34 & 100,0 & 59 & 96,7 & \\
\hline \multicolumn{8}{|l|}{ Alunos } \\
\hline Sim & 7 & 25,9 & 7 & 20,6 & 14 & 23,0 & \multirow{2}{*}{0,622} \\
\hline Não & 20 & 74,1 & 27 & 79,4 & 47 & 77,0 & \\
\hline \multicolumn{8}{|c|}{ Instituições externas } \\
\hline Sim & 4 & 14,8 & 0 & 0 & 4 & 6,6 & \multirow{2}{*}{0,020} \\
\hline Não & 23 & 85,2 & 34 & 100,0 & 57 & 93,4 & \\
\hline
\end{tabular}

*Questão admitiu respostas múltiplas

NOTA: Professores que abordaram pelo menos um dos vinte temas. 
A Tabela 4 apresenta a distribuição percentual dos professores do ensino fundamental por grupo de escolas, segundo a realização ou não de cada um dos nove tipos de projetos considerados na pesquisa.

Tabela 4 - Distribuição percentual dos professores do ensino fundamental por grupo de escolas, segundo tipos de projetos desenvolvidos.

\begin{tabular}{|c|c|c|c|c|c|c|c|}
\hline \multirow{3}{*}{ Projetos* } & \multicolumn{4}{|c|}{ Grupo de escola } & & & \multirow{2}{*}{$\begin{array}{c}\text { Teste } \\
\text { quiquadrado }\end{array}$} \\
\hline & \multicolumn{2}{|c|}{$\begin{array}{l}\text { sujeita a } \\
\text { enchentes }\end{array}$} & \multicolumn{2}{|c|}{$\begin{array}{l}\text { não sujeita a } \\
\text { enchentes }\end{array}$} & \multicolumn{2}{|c|}{ Total } & \\
\hline & $\mathbf{n}$ & $\%$ & $\mathbf{n}$ & $\%$ & $\mathbf{n}$ & $\%$ & p-valor \\
\hline \multicolumn{8}{|l|}{$\begin{array}{l}\text { Montagem de acervo bibliográfico } \\
\text { físico e digital sobre o tema na } \\
\text { escola }\end{array}$} \\
\hline Sim & 1 & 3,7 & 2 & 5,9 & 3 & 4,9 & \multirow{2}{*}{0,696} \\
\hline Não & 26 & 96,3 & 32 & 94,1 & 58 & 95,1 & \\
\hline \multicolumn{8}{|l|}{$\begin{array}{l}\text { Pesquisas em várias fontes de } \\
\text { informação }\end{array}$} \\
\hline Sim & 14 & 51,9 & 23 & 67,6 & 37 & 60,7 & \multirow{2}{*}{0,210} \\
\hline Não & 13 & 48,1 & 11 & 32,4 & 24 & 39,3 & \\
\hline \multicolumn{8}{|l|}{ Montagem de peças de teatro } \\
\hline Sim & 4 & 14,8 & 4 & 11,8 & 8 & 13,1 & \multirow{2}{*}{0,726} \\
\hline Não & 23 & 85,2 & 30 & 88,2 & 53 & 86,9 & \\
\hline \multicolumn{8}{|l|}{$\begin{array}{l}\text { Concurso de desenhos e/ou fotos } \\
\text { e/ou redação }\end{array}$} \\
\hline Sim & 2 & 7,4 & 4 & 11,8 & 6 & 9,8 & \multirow{2}{*}{0,570} \\
\hline Não & 25 & 92,6 & 30 & 88,2 & 55 & 90,2 & \\
\hline \multicolumn{8}{|l|}{$\begin{array}{l}\text { Criação de jogos temáticos físicos } \\
\text { ou digitais }\end{array}$} \\
\hline Sim & 1 & 3,7 & 1 & 2,9 & 2 & 3,3 & \multirow{2}{*}{0,868} \\
\hline Não & 26 & 96,3 & 33 & 97,1 & 59 & 96,7 & \\
\hline \multicolumn{8}{|l|}{$\begin{array}{l}\text { Atividades de prevenção com a } \\
\text { comunidade do entorno }\end{array}$} \\
\hline Sim & 2 & 7,4 & 2 & 5,9 & 4 & 7,4 & \multirow{2}{*}{0,811} \\
\hline Não & 25 & 92,6 & 32 & 94,1 & 57 & 92,6 & \\
\hline \multicolumn{8}{|l|}{ Ciclo de palestras com especialistas } \\
\hline Sim & 4 & 14,8 & 2 & 5,9 & 6 & 9,8 & \multirow{2}{*}{0,245} \\
\hline Não & 23 & 85,2 & 32 & 94,1 & 55 & 90,2 & \\
\hline \multicolumn{8}{|l|}{$\begin{array}{l}\text { Elaboração de cartilhas sobre riscos } \\
\text { e prevenção }\end{array}$} \\
\hline $\operatorname{Sim}$ & 2 & 7,4 & 4 & 11,8 & 6 & 9,8 & \multirow{2}{*}{0,570} \\
\hline Não & 25 & 92,6 & 30 & 88,2 & 55 & 90,2 & \\
\hline \multicolumn{8}{|l|}{$\begin{array}{l}\text { Mobilização social para melhoria } \\
\text { da segurança da comunidade }\end{array}$} \\
\hline Sim & 2 & 7,4 & 1 & 2,9 & 3 & 4,9 & \multirow{2}{*}{0,423} \\
\hline Não & 25 & 92,6 & 33 & 97,1 & 58 & 95,1 & \\
\hline
\end{tabular}

*Questão admitiu respostas múltiplas

NOTA: Professores que abordaram pelo menos um dos vinte temas.

O tipo de projeto que os professores mais desenvolveram em ambos os grupos de escolas foi a pesquisa em várias fontes de informação (grupo 1: 51,9\% vs grupo 2: 
67,6\%). No grupo 1, os tipos de projeto menos desenvolvidos foram montagem de acervo bibliográfico físico e digital $(3,7 \%)$ e criação de jogos temáticos físicos ou digitais $(3,7 \%)$, enquanto no grupo 2 , os projetos menos desenvolvidos foram: criação de jogos temáticos físicos ou digitais (2,9\%) e mobilização social para melhoria da segurança da comunidade (2,9\%). Para todos os projetos pesquisados, não foram observadas diferenças estatisticamente significantes entre a proporção de professores que desenvolveram projetos em ambos os grupos de escolas ( $p$-valor $>0,10$ ).

A Tabela 5 apresenta a distribuição percentual dos professores do ensino fundamental por grupo de escolas, segundo a existência ou não de cada característica dos projetos.

Tabela 5 - Distribuição percentual dos professores do ensino fundamental por grupo de escolas, segundo as características dos projetos desenvolvidos pela escola.

\begin{tabular}{|c|c|c|c|c|c|c|c|}
\hline \multirow{3}{*}{ Características dos projetos* } & \multicolumn{4}{|c|}{ Grupo de escola } & \multirow{2}{*}{\multicolumn{2}{|c|}{ Total }} & \multirow{3}{*}{$\begin{array}{c}\text { Teste } \\
\text { quiquadrado } \\
\text { p-valor } \\
\end{array}$} \\
\hline & \multicolumn{2}{|c|}{$\begin{array}{c}\text { sujeita a } \\
\text { enchentes }\end{array}$} & \multicolumn{2}{|c|}{$\begin{array}{c}\text { não sujeita a } \\
\text { enchentes }\end{array}$} & & & \\
\hline & $\mathbf{n}$ & $\%$ & $\mathbf{n}$ & $\%$ & $\mathbf{n}$ & $\%$ & \\
\hline \multicolumn{8}{|c|}{$\begin{array}{l}\text { Projetos desenvolvidos pela escola: } \\
\text { de vez em quando e geralmente em } \\
\text { datas comemorativas }\end{array}$} \\
\hline Sim & 4 & 25,0 & 10 & 41,7 & 14 & 35,0 & \multirow{2}{*}{0,279} \\
\hline Não & 12 & 75,0 & 14 & 58,3 & 26 & 65,0 & \\
\hline \multicolumn{8}{|c|}{$\begin{array}{l}\text { Projetos desenvolvidos pela escola } \\
\text { de forma continuada }\end{array}$} \\
\hline Sim & 11 & 68,8 & 13 & 54,2 & 24 & 60,0 & \multirow{2}{*}{0,356} \\
\hline Não & 5 & 31,3 & 11 & 45,8 & 16 & 40,0 & \\
\hline \multicolumn{8}{|c|}{$\begin{array}{l}\text { Os projetos proporcionam troca de } \\
\text { conhecimentos entre escola e } \\
\text { comunidade }\end{array}$} \\
\hline Sim & 6 & 37,5 & 16 & 66,7 & 22 & 55,0 & \multirow{2}{*}{0,069} \\
\hline Não & 10 & 62,5 & 8 & 33,3 & 18 & 45,0 & \\
\hline \multicolumn{8}{|c|}{$\begin{array}{l}\text { Os projetos, em geral, têm uma } \\
\text { dimensão apenas teórica }\end{array}$} \\
\hline Sim & 1 & 6,3 & 2 & 8,3 & 3 & 7,5 & \multirow{2}{*}{0,806} \\
\hline Não & 15 & 93,8 & 22 & 91,7 & 37 & 92,5 & \\
\hline
\end{tabular}

*Questão admitiu respostas múltiplas

NOTA: Professores que desenvolveram ao menos um dos projetos pesquisados, entre aqueles que abordaram pelo menos um dos vinte temas.

Observou-se que 68,8\% dos professores das escolas sujeitas a enchentes (grupo 1) responderam que seus projetos são desenvolvidos de forma continuada na escola; $37,5 \%$ responderam que os projetos proporcionam troca de conhecimentos entre escola e comunidade e $25,0 \%$ responderam que os projetos são desenvolvidos de 
vez em quando e geralmente em datas comemorativas na escola. Com relação aos professores da escola não sujeita a enchentes (grupo 2), 66,7\% responderam que os projetos desenvolvidos proporcionam troca de conhecimentos entre escola $e$ comunidade; 54,2\% responderam que seus projetos são desenvolvidos de forma continuada na escola; e 41,7\% responderam que os projetos são desenvolvidos de vez em quando e geralmente em datas comemorativas na escola. Comparando os dois grupos de escolas verificou-se diferença estatisticamente significante entre o percentual de professores cujos projetos desenvolvidos proporcionam troca de conhecimentos entre escola e comunidade ( $\mathrm{p}$-valor $=0,069$ ), sendo que este percentual foi menor para o grupo de escolas sujeitas a enchentes (grupo 1: $37,5 \%$ vs grupo 2: 66,7\%).

\section{DISCUSSÃO DOS RESULTADOS}

Este estudo buscou analisar a percepção dos professores de cinco escolas no município de Itaboraí-RJ sobre riscos de acidentes e desastres, tomando por base um conjunto de informações sobre temas relacionados à defesa civil, com foco na questão das enchentes, abordados pelos professores em suas disciplinas, meios utilizados para a inclusão dos temas, origem da iniciativa para desenvolvimento de atividades de prevenção e tipos de projetos ligados à defesa civil desenvolvidos na escola, obtidas através de uma pesquisa quantitativa dirigida aos professores das escolas.

Além disso, a partir de uma pesquisa qualitativa dirigida à direção das escolas e de uma avaliação fotográfica do entorno, classificou as escolas em dois grupos de análise (grupo 1: quatro escolas sujeitas a enchentes vs grupo 2: uma escola sujeita a enchente) a fim de comparar a percepção dos professores. Os resultados sugerem a baixa percepção de riscos de desastres dos professores de ensino fundamental de ambos os grupos de escolas municipais.

Mesmo sendo profissionais formadores de opinião e considerados agentes potenciais para a disseminação do conhecimento, verificou-se a baixa percepção deste segmento sobre riscos de acidentes e desastres, devida, entre outros fatores, a pequena proporção de professores abordando temas relacionados à defesa civil nos dois grupos. Dos vinte temas apresentados na pesquisa, somente o tema Poluição da água foi o mais desenvolvido pelos professores em ambas as escolas.

Observou-se que uma grande proporção de professores não está desenvolvendo importantes temas no contexto de enchentes, dentre eles os relativos a Chuvas intensas, Enxurradas, Deslizamentos de terra, Enchentes e inundações, Raios, Desastres 
naturais, Normas de prevenção de desastres e Doenças epidêmicas. Este resultado demonstrou que, temas relacionados aos tipos de desastres mais comuns como enchentes e inundações, incidentes em nosso território, não estão sendo debatidos, nem estão tendo a importância que deveriam ter. Este fato pode ser reflexo de uma falta de cultura relacionada a desastres no país, tal como apontado por FGV (2012), ao revelar, com base em entrevistas a pesquisadores e especialistas, algumas fragilidades dentre as quais se destacam: 1) a ausência de uma cultura de prevenção de riscos no país, resultante da baixa percepção dos mesmos e dos poucos registros de desastres no sistema nacional e na memória coletiva; 2) a não consolidação da percepção de riscos dos tomadores de decisão e da população brasileira, apesar do grande impacto social dos grandes desastres ocorridos recentemente no Brasil; 3) a inexistência de uma política nacional de gestão de riscos no país.

Na comparação entre grupos de escolas, verificou-se que não foi observada diferença entre a proporção de professores que abordaram os temas relacionados à questão de enchentes como Mudanças Climáticas, Chuvas intensas, Enxurradas, Deslizamentos de terra, Enchentes e inundações, Raios, Desastres naturais e Doenças epidêmicas. Entretanto, observou-se diferença significativa entre as proporções de professores que abordaram o tema Riscos de acidentes, o que é visto positivamente no âmbito da defesa civil.

A minoria de professores desenvolvendo temas relacionados à questão de enchentes, em escolas sujeitas a enchentes, indica uma situação grave, pois segundo Castro (1999), uma baixa percepção de riscos representa a mais grave vulnerabilidade social das populações no que diz respeito à intensificação dos desastres. Como a minoria dos professores desenvolve tais temas, há necessidade de implantação de programas nas escolas, tal como proposto por Lima (2006), visando sensibilizar e conscientizar os professores, potencializando uma mudança cultural direcionada à responsabilidade social e necessidade de proteção diante de ameaças. Segundo Lima (2006), a escola é considerada um espaço de implantação de programas destinados a divulgar ações de defesa civil, dentro do público jovem, por ser um organismo social, integrante da comunidade, dispondo de recursos físicos, humanos e materiais.

Dentre os meios de inclusão dos temas abordados pelos professores em suas disciplinas (realização de pesquisa, produção de material, exploração de conteúdos da disciplina ministrada, uso de problemas da comunidade ou da escola, realização de palestras/seminários, desenvolvimento com parcerias, abordagem da questão da 
resiliência) observou-se em ambas as escolas que os mais utilizados pelos professores foram: 1) exploração de conteúdos da disciplina ministrada; 2) realização de pesquisa; 3) uso de problemas da comunidade ou da escola e, 4) produção de material.

Com relação aos tipos de projetos desenvolvidos em ambos os grupos de escolas, verificou-se a pequena proporção de professores que os desenvolvem. $A$ pesquisa em várias fontes de informação foi o único projeto mais desenvolvido dentre os professores de cada grupo. Os projetos que envolvem a montagem de acervo bibliográfico físico e digital, a criação de jogos temáticos físicos ou digitais assim como os projetos que envolvem os alunos na temática a mobilização social para melhoria da segurança da comunidade tiveram pouca representatividade no ambiente escolar.

Com relação às características dos projetos desenvolvidos na escola, o estudo revelou que a minoria dos professores das escolas sujeitas a enchentes, informou que "os projetos desenvolvidos na escola têm uma dimensão apenas teórica".

Para as escolas analisadas, observou-se que existe motivação por parte da direção para o desenvolvimento de atividades de prevenção de riscos no âmbito das escolas, uma vez que a maioria dos professores pesquisados, de ambos os grupos de escolas, informou que a direção proporciona tempo para atividades especiais: grupo 1: 93,9\% vs grupo 2: 89,2\% (dados não tabulados). Observou-se também que os professores ao serem indagados sobre sua motivação para elaborar e desenvolver projetos e o seu interesse em receber capacitação em temas relacionados à defesa civil, a maioria deles, nos dois grupos de escolas, informou estar motivada: grupo $1=84,8 \%$ vs grupo $2=73,0 \%$ (dados não tabulados), sendo que nas escolas sujeitas a enchentes $64,3 \%$ dos professores motivados gostariam de receber capacitação, enquanto que na escola não sujeita a enchentes, esse percentual foi de 59,3\%.

\section{CONCLUSÕES E RECOMENDAÇÕES}

O presente artigo permitiu a identificação da necessidade de se incentivar a participação e capacitação de professores em projetos voltados à defesa civil, principalmente naqueles que abordam a questão de enchentes e inundações. Possibilitou ainda reconhecer a necessidade de se desenvolver programas tais como o sugerido por Lima (2006), visando conscientizar a comunidade sobre a importância de sua participação ativa na identificação e solução de problemas. 
Uma das limitações encontradas no presente estudo refere-se ao tamanho reduzido da amostra. Parte dos professores que aceitaram participar da pesquisa respondeu ao questionário de modo equivocado e por isso, foram excluídos da análise. Ao tentar contatá-los para recuperar as informações, já não faziam parte do corpo docente por término de contrato.

Outro ponto que deve ser ressaltado é que a baixa proporção de professores desenvolvendo projetos pode ser devida, em parte, ao reduzido tempo regular semanal do professor nessas escolas, uma vez que para implantação destes é necessário ter tempo disponível para executá-los juntamente com os alunos. Além disso, para o professor abordar temas de defesa civil em suas disciplinas ele precisa estar motivado e ser capacitado, para desenvolver outras atividades, além da sua função básica de ensinar os conteúdos da sua disciplina, dentro de uma carga horária fixada.

A motivação e engajamento das pessoas envolvidas no processo de mudança cultural é outro fator importante para o desenvolvimento de projetos desse tipo, mesmo quando alocados em escolas, exigem o envolvimento da família, da comunidade, da mídia, do governo, dos professores, dos funcionários e dos alunos, algo nada fácil pelo descrédito existente entre a comunidade em geral e órgãos promotores do governo. De qualquer forma, o professor, como formador de opinião de qualidade, é a chave fundamental nesse processo.

Por fim, diante dos resultados alcançados, recomenda-se a capacitação dos professores e diretores de escolas na educação voltada para a percepção de temas relacionados à defesa civil, especificamente às enchentes e inundações.

\section{REFERÊNCIAS BIBLIOGRÁFICAS}

CASTRO, A. L. C. Manual de planejamento em Defesa Civil. Brasília: Ministério da Integração Nacional, Secretaria de Defesa Civil, 1999. v. 1. Disponível em: $<$ http://www.defesacivil.mg.gov.br/conteudo/arquivos/manuais/Manuais-de-DefesaCivil/Manual-PLANEJAMENTO-1.pdf>. Acessado em: 02 de outubro de 2012.

CEPED/UFSC. Promoção da cultura de riscos de desastres: Relatório Final. Centro Universitário de Estudos e Pesquisas sobre Desastres da Universidade Federal de Santa Catarina. Florianópolis: CEPED/UFSC, 2012. 121p. Disponível em: <http://www.ceped.ufsc.br/sites/default/files/projetos/final_pcrd.pdf>. Acessado em: 21 de fevereiro de 2013. 
FGV. Plano Nacional de Gestão de Riscos e Resposta a Desastres (PNGRD-2012). Fundação Getúlio Vargas, 2012. Disponível em: 〈www.fgv.br/fgvprojetos〉. Acesso em 18 de março de 2013.

LIMA, J. N. A. Defesa civil na escola. Brasília: Secretaria Nacional de Defesa Civil, 2006. 233p. Monografia (Curso de Especialização em Planejamento e Gestão em Defesa Civil), Universidade Federal de Santa Catarina. Santa Catarina, 2006. Disponível em: <http://www.crpsp.org.br/portal/comunicacao/diversos/mini_cd_oficinas/pdfs/DefesaCivil-Na-Escola.pdf>. Acessado em: 15 de setembro 2012.

MARROIG, A. C., DEMOLINARI, H. C., ANDRADAS, M.F.L., BARK, D.C., SALES, L.M., JUNIOR, D.P.S., VELLOSO, M.P, LETA, F.R. Reflexões sobre sustentabilidade Sócio-econômica-Ambiental considerando o caso Comperj. CIBEM 10, Porto, Portugal, 2011. Disponível em: <http://www.uff.br/petmec/pet/cibem_comperj_final.pdf>. Acessado em: 15 de janeiro de 2013. 